\title{
COVID-19 E O PACTO COLETIVO EM IMUNIZAÇÃO: ESTRATÉGIAS, ÊXITOS E DESAFIOS DO PROGRAMA NACIONAL DE IMUNIZAÇÕES
}

\author{
Sheila Aparecida Ferreira Lachtim' \\ ORCID: 0000-0002-3323-5776 \\ Adriana Lopes Elias" \\ ORCID: 0000-0003-0696-3951 \\ Kássia Janara Veras Lima" \\ ORCID: 0000-0001-8952-5927 \\ Ramon da Costa Saavedra"II \\ ORCID: 0000-0002-7336-2825 \\ Carla Andrea Trapélv \\ ORCID: 0000-0002-3272-6565
}

'Escola de Enfermagem, Universidade Federal de Minas Gerais. Belo Horizonte, MG.

"Associação Brasileira de Enfermagem - ABEn-AM. Manaus, AM.

'"Sociedade Brasileira Imunizações - SBIm. Salvador, BA.

"Escola de Enfermagem, Universidade de São Paulo. São Paulo, SP.

Autora Correspondente: Sheila Aparecida Ferreira Lachtim E-mail: Sheila.massardi@gmail.com

Como citar: Lachtim SAF, Elias AL, Lima KJV, et al. Covid-19 e o pacto coletivo em imunização: estratégias, êxitos e desafios do Programa Nacional de Imunizações. In: Silva TMR, Lima MG, (Orgs.). Estratégias de vacinação contra a COVID-19 no Brasil: capacitação de profissionais e discentes de enfermagem. Brasilia, DF: Editora ABen; 2021. P 31-40. (Série enfermagem e pandemias, 6). https://doi.org/10.51234/aben.21.e08.c04

Revisora: Mônica Levi. Primeira Tesoureira da Sociedade Brasileira Imunizações - SBIm na gestão 2019-2020.

\section{INTRODUÇÃO}

O Programa Nacional de Imunizações (PNI) antecede a criação do Sistema Único de Saúde (SUS), porém é com a implementação da rede capilarizada de atenção primária à saúde que ele consegue alcançar um maior número de pessoas e desponta como o maior programa público de imunizações no mundo. Nesse momento pandêmico, há duas formas de combater o avanço do vírus: as medidas não farmacológicas - de higiene das mãos, uso de máscara e distanciamento social; e as vacinas contra COVID-19, que possuem alta eficácia para evitar o desfecho de óbito. Por isso, a luta não se reduz a intenção de eliminar um vírus, mas inclui a defesa do SUS e do PNI.

Esse capítulo irá discorrer sobre a história e o êxito do PNI, discutir as dificuldades enfrentadas na atualidade e o desafio de avançar com a imunização contra COVID-19.

\section{PNI E SUS (BREVE HISTÓRICO)}

A vacinação é uma estratégia consolidada de enfrentamento de doenças infeciosas. A história da vacinação se inicia em 1976 com o trabalho de Edward Jenner, médico de origem inglesa, que, ao inocular secreções de pústulas de vacas contaminadas pelo vírus da varíola em um menino de oito anos de idade, identificou que a criança desenvolveu uma pequena lesão, mas não adquiriu a doença, estabelecendo um importante marco para as descobertas imunológicas ${ }^{(1)}$.

No Brasil, amostras de vírus para a vacinação chegaram por volta de 1840 com o objetivo de proteger as famílias nobres. Mais tarde, o cirurgião Barão de Pedro Afonso criou um instituto privado para o preparo de vacina antivariólica e foi encarregado de estabelecer o Instituto Municipal Soroterápico no Rio de Janeiro, que foi denominado posteriormente de Instituto Oswaldo $\mathrm{Cruz}^{(2)}$. 
Nesta época, vários problemas sanitários atingiam concomitantemente a população brasileira. Entre 1902 e 1904, o presidente Rodrigues Alves tomou medidas drásticas, com a intenção de fazer uma remodelação urbana que auxiliasse no combate as epidemias. Entretanto, as demolições de cortiços e casebres desalojaram e empurraram a população para os barrancos e morros na periferia, expandindo as favelas ${ }^{(3)}$.

Em 1904, a capital do país sofria com uma epidemia de varíola que ficou conhecida como "túmulo de estrangeiros". Para solucionar a questão, Oswaldo Cruz conseguiu, por meio de lei aprovada pelo congresso, que a vacinação contra a varíola fosse obrigatória. Entretanto, essa foi realizada sem os devidos esclarecimentos para a população. As brigadas sanitárias entravam nas casas e vacinavam as pessoas utilizando a força. A sociedade já revoltada com a demolição das suas casas deu início à chamada Revolta da Vacina. Para alguns historiadores, a Revolta da Vacina foi um desfecho resultante do processo de modernização excludente concentrado e não uma simples reação explosiva de uma massa ignorante que era contra o progresso, como foi considerado na época(3).

Essa forma autoritária de conduzir ações em saúde contra a varíola não obteve sucesso ao longo do tempo e o Brasil chegou na década de 1960 com um incômodo perfil epidemiológico perante a comunidade internacional. Naquele momento, era o único do continente americano, onde a doença infecciosa ainda era endêmica. Assim, em 1962, atendendo as recomendações da Organização Mundial da Saúde (OMS) e da Organização Pan-Americana da Saúde (OPAS) para eliminação da enfermidade, o Brasil criou a Campanha Nacional de Controle da Varíola (CNCV), órgão substituído em 1966 pela Campanha de Erradicação da Varíola (CEV), responsável por coordenar a execução de ações de vacinação em massa em todo o país ${ }^{(4)}$.

A CEV coordenou a organização e execução de campanhas de vacinação em massa em todos os municípios brasileiros entre 1966 e 1971. Em 1973 o Brasil recebeu um certificado de erradicação da varíola, ressaltando que em anos anteriores outras iniciativas haviam fracassado por falta de estrutura profissionalizada e autonomia gerencial ${ }^{(5)}$.

É importante assinalar que a CEV contribuiu para a organização de uma nova abordagem no controle das doenças imunopreveníveis por meio do planejamento operacional, monitoramento dos resultados e da situação epidemiológica. Introduziu o conceito de "vigilância epidemiológica" baseado na produção, análise e divulgação de informações que apoiassem a tomada de decisões de forma coordenada entre as diversas instâncias de gestão. Tal experiência foi oportunamente apropriada pelo Plano Nacional de Controle de Poliomielite em 1971 e ganhou fôlego com a criação do Programa Nacional de Imunização (PNI), no mesmo ano da certificação de erradicação da varíola no Brasil|(5).

A criação do PNI em 1973 deu-se no âmbito do processo de formulação de grandes programas nacionais, na gestão do ministro Mário Machado de Lemos (1972-74). Ele estava vinculado a Divisão Nacional de Epidemiologia e Estatística de Saúde (DNEES), que fazia parte do Departamento Nacional de Profilaxia e Controle de Doenças, no interior do Ministério da Saúde ${ }^{(6)}$ Tinha como objetivo coordenar as ações de imunizações que se caracterizavam, até então, pela descontinuidade, pelo caráter episódico, por meio de campanhas pontuais e pela reduzida área de cobertura ${ }^{(1)}$. Até então, as atividades de vacinação estavam divididas entre os programas verticais do Ministério da Saúde tais como varíola, tuberculose e febre amarela; e as outras eram executadas através das secretarias estaduais de saúde, como poliomielite, sarampo e vacina tríplice bacteriana ${ }^{(6)}$.

O PNI passou a coordenar também as atividades de imunizações desenvolvidas rotineiramente na rede de serviços e a legislação específica sobre imunizações e vigilância epidemiológica (Lei 6.259, de 30 de outubro de 1975, e pelo Decreto $n^{\circ} 78.231$, de 12 de agosto de 1976), dando ênfase às atividades permanentes de vacinação e contribuindo para fortalecer institucionalmente o Programa ${ }^{(1)}$. A instituição da legislação específica sobre a vigilância epidemiológica se fez necessária diante da necessidade de organização das ações após uma epidemia de meningite meningocócica, que teve seu principal foco em São Paulo e Rio de Janeiro e provocou centenas de mortes, em $1974^{(6)}$. 
Vale ressaltar que a década de 1970 se conformou em um período em que existia a disputa entre diversos modelos e projetos do campo da saúde. Foi um tempo de introdução de propostas pautadas no planejamento como instrumento do desenvolvimento de políticas públicas e surgimento de iniciativas que defendiam universalização dos cuidados em saúde e da estruturação de um novo campo de saber e práticas, conformando o movimento sanitário brasileiro(6).

Assim, na base da estruturação das campanhas de vacinação e do próprio PNI verificavam-se ao menos dois movimentos: o que defendia o modelo vertical, centralizador e campanhista; e o que identificava nessa estratégia uma síntese de modelo biomédico a ser combatido e transformado. Tais críticas se ampliavam em direção ao questionamento do próprio papel das políticas públicas em uma sociedade cada vez mais desigual. Os questionamentos residiam no fato de que as ações focalizadas em campanhas de vacinação protegem o indivíduo contra determinadas doenças, mas não intervêm na determinação de base econômica e social que estão na raiz do adoecimento dos grupos sociais ${ }^{(6)}$. Nessa perspectiva, o movimento sanitarista reivindicava que ações como as campanhas viessem acompanhadas de reformas sociais e combate à desigualdade. Entende-se que as campanhas devem vir acompanhadas de ações de monitoramento contínuas e de políticas setoriais que atendam às necessidades relacionadas às suas condições de vida e trabalho.

A partir da construção do SUS, o PNI se apresenta como programa que passa a contribuir para o fortalecimento do sistema por meio dos movimentos de descentralização que colocou o município como o executor primário e direto das ações de saúde, entre elas as de vacinação. Isso fica explícito no objetivo principal do PNI que é o de "oferecer todas as vacinas com qualidade a todas as crianças que nascem anualmente em nosso país, tentando alcançar coberturas vacinais de $100 \%$ de forma homogênea em todos os municípios e em todos os bairros"(6). Nesse cenário, o PNI tem garantido a oferta de vacinas seguras e eficazes para todos os grupos populacionais que são alvo de ações de imunização, por meio de ações que nortearam e organizaram os calendários vacinais para todas as faixas etárias e também para grupos específicos, considerando situação epidemiológica, idade, fatores de risco, vulnerabilidades específicas e áreas geográficas, aumentando assim a eficácia do programa na prevenção de doenças imunopreveníveis(7).

$\mathrm{Na}$ esfera federal, o PNI está atualmente sob a responsabilidade da Coordenação-Geral do Programa Nacional de Imunizações (CGPNI), do Departamento de Vigilância das Doenças Transmissíveis (DEVIT), da Secretaria de Vigilância em Saúde (SVS), do Ministério da Saúde ${ }^{(8)}$.

Com expansão gradativa ao longo dos anos, o calendário de vacinação era inicialmente composto por apenas sete tipos de imunobiológicos. Atualmente, o Brasil destaca-se como um dos países com maior oferta de vacinas à população, de forma gratuita e com abrangência em todas as fases da vida, conforme calendários de vacinação instituídos para crianças, adolescentes, adultos, grávidas e idosos ${ }^{(1)}$. $\mathrm{O}$ acesso aos imunobiológicos no país ocorre no âmbito da atenção primária à saúde por meio das salas de vacinas distribuídas em todos os municípios. Além do calendário básico, há calendários especiais para populações com maior vulnerabilidade, tais como indígenas e pessoas com condições especiais de saúde, sendo atendidos esses últimos nos Centros de Referência de Imunobiológicos Especiais (CRIE) ${ }^{(9)}$.

As campanhas de vacinação continuam sendo estratégia valiosa para redução das doenças infectocontagiosas já que, somadas à vacinação rotineira, geram um grande impacto na proteção coletiva e interrupção da cadeia de transmissão de doenças, tais como: influenza; poliomielite; sarampo e papiloma-vírus humano (HPV). Geralmente, estabelece-se uma meta de vacinação para um curto espaço de tempo, realizando a vacinação em massa para o público-alvo definido para cada campanha ${ }^{(1)}$.

Para operacionalizar a inserção de novas vacinas, mantendo a sustentabilidade, credibilidade e acesso universal aos imunobiológicos no país são considerados os critérios descritos na Tabela 1. 
Tabela 1 - Critérios para operacionalizar a inserção de novas vacinas. Brasil, 2021

\begin{tabular}{|c|c|}
\hline $\begin{array}{l}\text { Análise do perfil } \\
\text { epidemiológico de uma doença }\end{array}$ & $\begin{array}{l}\text { Estudar a gravidade, taxas de prevalência ou incidência, morbimortalidade e } \\
\text { dinâmica das doenças; }\end{array}$ \\
\hline Eficácia e segurança da vacina & $\begin{array}{l}\text { Avaliar a adequação dos estudos conforme as particularidades da população-alvo, } \\
\text { avaliando-se o risco-benefício da introdução da vacina no país; }\end{array}$ \\
\hline Critérios socioeconômicos & $\begin{array}{l}\text { Análise dos custos da vacina e dos custos relacionados a esta doença que podem } \\
\text { ser reduzidos; }\end{array}$ \\
\hline Análise das comissões & $\begin{array}{l}\text { Decisão é subsidiada pela análise técnica do Conselho técnico formado por } \\
\text { especialistas na área de imunização. Representantes de instituições ou organizações } \\
\text { reconhecidas nacional e internacionalmente por sua atuação na área de imunizações; }\end{array}$ \\
\hline Tecnológicos & $\begin{array}{l}\text { Avaliações técnicas e econômicas, relativas ao diagnóstico sobre a capacidade } \\
\text { de produção e fornecimento sustentável da vacina no país, vislumbrando a } \\
\text { autossuficiência da produção. Estabelecem-se Parcerias para o Desenvolvimento } \\
\text { Produtivo (PDP) -cooperação entre instituições públicas e/ou privadas para o } \\
\text { desenvolvimento, transferência tecnológica para produção e capacitação produtiva. }\end{array}$ \\
\hline Garantia de financiamento & $\begin{array}{l}\text { Analisar a possibilidade de aporte financeiro sustentável para a aquisição, conservação } \\
\text { e aplicação dos novos imunobiológicos, considerando as três esferas de governo; }\end{array}$ \\
\hline $\begin{array}{l}\text { Execução das ações de } \\
\text { vacinação }\end{array}$ & $\begin{array}{l}\text { Analisar a capacidade de armazenamento e conservação nas três esferas de } \\
\text { governo, a fim de garantir a qualidade da vacina até o momento da aplicação; }\end{array}$ \\
\hline $\begin{array}{l}\text { Capacidade das equipes de } \\
\text { vacinação }\end{array}$ & $\begin{array}{l}\text { Planejar a capacitação dos profissionais envolvidos e estimar a necessidade de } \\
\text { captação de novos profissionais. }\end{array}$ \\
\hline
\end{tabular}

Fonte: Adaptado pelo autores (10-11).

É notória a contribuição do programa para o Sistema Único de Saúde (SUS), impactando na prevenção e/ou controle da incidência de doenças infectocontagiosas, na redução de hospitalizações, contribuindo diretamente para melhoria da saúde e qualidade de vida da população(1),(12).

Como parte desta evolução e fortalecimento do PNI, no decorrer dos anos, destaca-se a implantação do SI-PNI, que dispõe de controle nominal da situação vacinal de cada indivíduo, contribuindo para o monitoramento qualificado da cobertura vacinal no território e uma análise consistente do programa nas unidades federadas. Cada avanço do PNI consolida o sucesso do programa no âmbito da saúde pública e reafirma os princípios do SUS.

Em sua quinta década, o PNI acumulou inúmeras experiências exitosas e avanços. Entretanto, tem muitos desafios a enfrentar que já existiam antes mesmo do atual contexto sanitário da pandemia de COVID-19. Estes dizem respeito não apenas ao alcance da autossuficiência na produção de um número cada vez maior de vacinas, mas também à garantia de alcance da cobertura vacinal. A manutenção das altas taxas que eram alcançadas até alguns anos atrás, motivo de grande orgulho para o país e exemplo de estratégia de sucesso para outros países, tem sofrido obstáculos e temos visto redução progressiva nos últimos anos. Tem-se observado que a baixa adesão à vacinação vem se concentrando principalmente entre as camadas sociais médias e ricas da população. Seja por ideologia ou por desconhecimento, colocam em xeque a importância da vacinação e tem pouca ou nenhuma preocupação com a imunidade coletiva. Engajar as famílias de nível social mais elevado por meio de amplo debate da sociedade civil será fundamental para enfrentar esse desafio ${ }^{(13)}$.

Atualmente, movimentos populares antivacina surgem, pois à medida que a morbimortalidade por doenças imunopreveníveis decresce, os riscos associados a essas doenças tornam-se invisíveis a muitos, o que impacta o 
comportamento coletivo relativo à adesão aos calendários de vacinação instituídos, culminando em bolsões de suscetíveis a determinados agravos e o perigo de (re)surgimento de doenças já erradicadas ou controladas no país ${ }^{(12)}$.

Ao acompanhar a cobertura vacinal no país, observa-se a partir de 2016 uma queda de até 20 pontos percentuais no caso do sarampo ${ }^{(14)}$. Essa queda foi responsável pela reintrodução da doença no país, com surto que se iniciou em 2018. Em 2019, um ano após transmissão ativa não controlada com campanha de vacinação nacional, o Brasil perde a certificação de eliminação do sarampo. Desde 2018 até a semana epidemiológica 13/2021 o país somava mais de 40 mil casos da doença com circulação em pelo menos 25 estados ${ }^{(15)}$. Porém, não é apenas para o sarampo que houve redução da cobertura vacinal; pode-se observar quedas entre 10 e 20 pontos percentuais no calendário infantil para outras vacinas, tais como poliomielite, hepatite $A$, pentavalente e rotavírus.

Acredita-se que as quedas nas taxas de cobertura vacinal sejam multifatoriais. Além da falta de percepção da população da importância das vacinas para mantermos doenças sob controle ou erradicadas, outros fatores certamente estão presentes, entre eles: enfraquecimento do Sistema Único de Saúde (SUS); aspectos técnicos como a implantação do novo sistema de informação de imunização; horário de funcionamento das UBS, faltas temporárias de vacinas, aspectos sociais e culturais que afetam a aceitação da vacinação; fake news e movimentos antivacinas. Esses dois últimos são os principais responsáveis pela hesitação vacinal, situação que varia ao longo do tempo e pode apresentar especificidades em cada diferente contexto ${ }^{(16)}$.

\section{IMUNIZAÇÃO NO CONTEXTO DA PANDEMIA COVID-19}

No contexto da atual pandemia de COVID-19, que se configura como uma das maiores crises sanitárias globais, o mundo já acumula mais de 209 milhões de casos confirmados e de 4.39 milhões de óbitos, e o Brasil reporta mais de 20.5 milhões de casos e de 572 mil óbitos $^{(17)}$. Nesse cenário, as vacinas surgem trazendo a esperança de se tornarem a principal ferramenta para o enfrentamento da pandemia, permitindo o progressivo relaxamento das medidas de distanciamento social e suas implicações socioeconômicas, conforme avança a vacinação ${ }^{(18)}$. Assim, o Ministério da Saúde do Brasil elabora o Plano Nacional de Operacionalização da Vacinação contra a COVID-19 com um quantitativo limitado de doses, tornando necessário definir e escalonar os grupos prioritários para vacinação de acordo com: a) risco maior de formas graves e óbitos pela doença; b) necessidade de manutenção do funcionamento dos serviços de saúde e outros considerados essenciais e c) grupos com elevada vulnerabilidade social ${ }^{(19)}$.

Para tanto, a elaboração e execução de um plano de vacinação efetivo, que garanta o alcance de índices adequados de coberturas vacinais é fundamental para atingir os objetivos de cada fase estipulada no PNO. Afinal, o agente infeccioso não consegue manter taxa de reprodução elevada em uma população com baixo número de pessoas suscetíveis. Por isso a importância da vacinação em massa e com altas taxas de cobertura vacinal homogênea no país conferindo além do benefício individual da proteção, proteção solidária e coletiva, poupando inclusive os indivíduos não imunizados ${ }^{(20)}$.

A estimativa de uma meta de cobertura vacinal é calculada com base no conceito-chave de imunidade de rebanho ou imunidade coletiva, que determina que a existência de um grande número de pessoas protegidas garante menor probabilidade de o agente infeccioso circular, diminuindo inclusive o risco das pessoas não vacinadas adoecerem e evitando a ocorrência de epidemias mesmo que alguma transmissão ainda ocorra ${ }^{(20)}$.

Além disso, o nível de confiança e adesão a uma nova vacina varia ao longo do processo de sua implantação e disponibilização nos serviços de saúde. Inicialmente, se a incidência da doença é alta, o público, em geral, tende a procurar mais espontaneamente os serviços para receber a(s) dose(s) indicada(s), especialmente se a doença estiver associada à elevada morbimortalidade ${ }^{(21)}$.

Muitos são os desafios a serem superados no processo de vacinação contra COVID-19 no Brasil. A velocidade com a qual o vírus segue se disseminando em todas as regiões do país após um ano de pandemia indica a necessidade de uma condução única, coordenada pela esfera federal e em cooperação com os demais níveis 
de gestão, estadual e municipal ${ }^{(22)}$. Entretanto, o ritmo vagaroso que vem sendo impresso na campanha de vacinação desde janeiro de 2021, dificulta alcançar rapidamente o impacto necessário e oportuno a fim de impedir a alta transmissão viral na sociedade.

Soma-se a isso o fato, já apresentado, de que desde 2016 os indicadores de cobertura vacinal no Brasil vêm apresentando sucessivas quedas anuais. Diversos aspectos podem estar associados à essa situação, mas certamente a relutância em vacinar vem se constituindo em uma das principais preocupações das autoridades sanitárias. A hesitação vacinal não é novidade em países europeus e norte-americanos, mas surge mais recentemente no Brasil esse grave dificultador do êxito das estratégias de vacinação. A importância da hesitação vacinal é tão grande a ponto de ter sido considerada pela Organização Mundial da Saúde em 2019 uma das dez maiores ameaças à saúde global em 2019(22).

Destaca-se ainda a influência negativa que as denominadas fake news vem exercendo em todo o mundo e em diversas áreas, inclusive na saúde, por meio da disseminação de inverdades, boatos sem fundamentação científica ou fraudes comprovadas, como a mentira que relaciona a vacina contra o sarampo com o autismo. Estudo recente publicado pela Sociedade Brasileira de Imunizações (SBIm) em parceria com a Avaaz, com o objetivo de investigar a associação entre a desinformação e a queda nas coberturas vacinais verificadas nos últimos anos, revela que sete em cada dez brasileiros acreditam em ao menos uma afirmação imprecisa sobre vacinação, e que isso tende a ser determinante na tomada de decisão de não se vacinar. O cenário é tão preocupante que a pesquisa conclui que o país vive uma epidemia de desinformação associada à vacinação(24).

A comunicação adequada com a população, informando os reais benefícios de uma vacina, suas limitações e a importância da proteção individual e coletiva é um grande desafio a ser enfrentado, em função de questões geopolíticas envolvidas. A confiança popular nas vacinas com comprovação científica precisa ser mantida, sob pena de colocarmos em risco todas as conquistas obtidas no controle e eliminação de doenças em todo o mundo ${ }^{(25)}$. Entretanto, a experiência vivenciada com a pandemia de COVID-19 até o momento, colocou em xeque políticas públicas consistentes, construídas por décadas a partir da instituição do Sistema Único de Saúde (SUS), especificamente do Programa Nacional de Imunizações (PNI).

A campanha de vacinação contra a COVID-19 no país vem enfrentando inúmeros percalços, que perpassa desde a comunicação truncada entre governo federal e sociedade, até a escassez de imunobiológicos, passando por indícios de corrupção e superfaturamento, resultando em atrasos no recebimento de doses e impossibilidade de planejamento do cronograma de vacinação.

Mudanças repentinas, em curto espaço de tempo, resultaram no desalinhamento das ações entre os programas federal, estaduais e municipais. Outrossim, as orientações técnicas também não chegavam de maneira transparente e organizada nas salas de vacinação, onde a campanha de fato acontece ${ }^{(25)}$.

É imprescindível que a vacinação seja ofertada ao maior número de pessoas em um pequeno intervalo de tempo. Para tanto se deve otimizar a operacionalização da campanha de vacinação. Ou seja, as vacinas são estratégias coletivas que carecem de exímio planejamento e organização.

A comunidade científica mundial vive um momento histórico, marcado pelo inédito cenário de desenvolvimento acelerado de vacinas contra a COVID-19. De fato, o engajamento de cientistas, o uso de diferentes plataformas para produção de imunobiológicos, incluindo tecnologias utilizadas em oncologia e de estudos já avançados para outros vírus respiratórios como MERS e SARS, o volume de investimento financeiro realizado por países desenvolvidos, por indústria farmacêutica e por organizações não governamentais, trabalhando muitas vezes em parceria, possibilitou o desenvolvimento de vacinas seguras e eficazes em tempo recorde na história da produção e licenciamento de novas vacinas ${ }^{(18)}$.

Inicialmente, o Brasil aprovou duas vacinas contra COVID-19 para o uso emergencial, a Coronavac da farmacêutica chinesa Sinovac em parceria com o Instituto Butantan, e a ChAdOx1 nCoV-19 da farmacêutica AstraZeneca, que conta com a parceria da Universidade de Oxford e da Fiocruz. Vale ressaltar que as condições que permitem autorização temporária para uso emergencial das vacinas contra a COVID-19 no país 
estão normatizadas na RDC no. 444, de 10 de dezembro de 2020, que regula os critérios mínimos a serem cumpridos pelas empresas para submissão do pedido de autorização temporária de uso emergencial durante a vigência da emergência em saúde pública.

Por conta da política do governo federal de não priorização da imunização contra COVID-19, com recusa de propostas realizadas por algumas empresas e demora na resposta e intenção de aquisição de vacinas no mercado internacional, somadas a escassez de investimentos financeiros para o desenvolvimento e produção nacional da vacina, o país conseguiu comprar/produzir um número insuficiente de doses para imunizar toda a população até o momento.

No atual cenário de operacionalização da campanha, o governo federal vem realizando investimentos na produção da vacina do laboratório AstraZeneca/Oxford, em parceria com a Fundação Oswaldo Cruz - Fiocruz, que refere uma capacidade de produção diária de um milhão de vacinas, somado ao esforço do Instituto Butantan, que, em parceria com o laboratório produtor Sinovac da China, vem abastecendo de forma limitada a Campanha Nacional de Vacinação contra a COVID-19 em todo o território nacional.

Nesse contexto, a aquisição de novas doses de vacina mostra-se imprescindível para que se consiga alcançar o objetivo de imunizar pelo menos $90 \%$ de todos os grupos prioritários preconizados pelo plano nacional, uma vez que a realidade da distribuição de vacinas pelo Ministério da Saúde vem ocorrendo de forma escalonada, o que impacta nas coberturas vacinais com números pouco significativos para efetivação da campanha. Tal fato, exerce pressão sobre os estados e municípios que tentam no mercado internacional a aquisição de vacinas, seja por mecanismos próprios ou consórcios interestaduais, sob o amparo legal, previsto na Lei no 14.124, de 10 de março de 2021, que, além de autorizar os estados, municípios e o distrito federal a adquirir, a distribuir e a aplicar as vacinas contra a COVID-19 registradas, autorizadas para uso emergencial ou autorizadas excepcionalmente para importação, nos termos do art. 16 desta Lei, caso a União não realize as aquisições e a distribuição tempestiva de doses suficientes para a vacinação dos grupos previstos no Plano Nacional de Operacionalização da Vacinação contra a COVID-19.

Tabela 2 - Situação das vacinas no Brasil. Brasil, 2021

\begin{tabular}{|c|c|c|c|c|}
\hline Vacina & $\begin{array}{l}\text { Situação Registro } \\
\text { Anvisa }\end{array}$ & Tecnologia & $\begin{array}{l}\text { Intervalo Mínimo/ } \\
\text { nº doses }^{\circ}\end{array}$ & Observações \\
\hline $\begin{array}{l}\text { Comirnaty } \\
\text { Pfizer/Wyeth }\end{array}$ & $\begin{array}{l}\text { Registro concedido } \\
\text { em } 23 / 02 / 2021\end{array}$ & $\begin{array}{l}\text { RNA Mensageiro } \\
\text { sintético }\end{array}$ & 21 dias/ 2 doses & $\begin{array}{l}\text { Liberada para menores de } 12 \\
\text { anos }\end{array}$ \\
\hline $\begin{array}{l}\text { Coronavac } \\
\text { Butantan }\end{array}$ & $\begin{array}{l}\text { Uso emergencial em } \\
17 / 01 / 2021\end{array}$ & $\begin{array}{l}\text { Antígeno do vírus } \\
\text { inativado }\end{array}$ & 14-28 dias/2 doses & \\
\hline $\begin{array}{l}\text { Janssen } \\
\text { Cilag }\end{array}$ & $\begin{array}{l}\text { Uso emergencial em } \\
31 / 03 / 2021\end{array}$ & $\begin{array}{l}\text { Vetores de } \\
\text { adenovírus } \\
\text { sorotipo } 26 \text { (Ad26) }\end{array}$ & Dose única & $\begin{array}{l}\text { Válida por quatro meses e } \\
\text { meio quando armazenada na } \\
\text { temperatura entre } 2^{\circ} \mathrm{Ce} 8^{\circ} \mathrm{C}\end{array}$ \\
\hline $\begin{array}{l}\text { Astrazeneca } \\
\text { FioCruz/Oxford }\end{array}$ & $\begin{array}{l}\text { Registro definitivo } \\
\text { em } 12 / 03 / 2021\end{array}$ & $\begin{array}{l}\text { vetor adenovírus } \\
\text { recombinante. }\end{array}$ & 28-84 dias/2 doses & Contraindicada para gestantes \\
\hline Sputinik V & $\begin{array}{l}\text { Importação } \\
\text { controlada } \\
\text { (Lei 14.124/2021) }\end{array}$ & $\begin{array}{l}\text { Adenovírus D-26 } \\
\text { D-5 }\end{array}$ & $21 \mathrm{dias} / 2$ doses & $\begin{array}{l}\text { Faixa etária: indivíduos adultos } \geq \\
18 \text { anos e }<60 \text { anos. } \\
\text { Contraindicada para gestante, } \\
\text { puérperas, lactantes e indivíduos } \\
\text { com comorbidades }\end{array}$ \\
\hline
\end{tabular}




\begin{tabular}{l|l|l|l|l} 
Vacina & $\begin{array}{l}\text { Situação Registro } \\
\text { Anvisa }\end{array}$ & Tecnologia & $\begin{array}{l}\text { Intervalo Mínimo/ } \\
\mathbf{n}^{\circ} \text { doses }\end{array}$ & Observações \\
\hline Covaxin & $\begin{array}{l}\text { Processo de } \\
\text { importação } \\
\text { suspenso (medida } \\
\text { cautelar) }\end{array}$ & vírus inativado & 28 dias/ 2 doses & $\begin{array}{l}\text { Faixa etária: indivíduos adultos } \geq \\
18 \text { anos e }<60 \text { anos. } \\
\text { Contraindicada para gestante, } \\
\text { puérperas, lactantes e indivíduos } \\
\text { com comorbidades }\end{array}$
\end{tabular}

Fonte: Tabela elaborada pelos autores.

O Plano Nacional de Operacionalização da Vacinação contra COVID-19 estima a vacinação de 77.279 .644 milhões de pessoas que pertencem aos grupos prioritários distribuídos em quatro fases da campanha. Os grupos prioritários foram definidos justamente pela escassez na disponibilidade da vacina e tem dois objetivos: imunizar a população de maior risco de agravamento e óbito, além de manutenção da mão de obra essencial, tais como trabalhadores de saúde e forças de segurança ${ }^{(19)}$. Cerca de $55,58 \%$ da população brasileira recebeu a primeira dose de alguma vacina contra COVID-19 e 24,6\% estão totalmente imunizados com duas doses ou dose única. Em números absolutos significa que desde de 17/01/2021 até 19/08/2021, ou seja, em sete meses foram aplicadas um total (somando primeira dose, segunda dose e dose única) de 169.278.999 doses de vacina.

\section{PROCESSO DE LOGÍSTICA}

O PNI possui uma complexa logística para a distribuição de vacinas por todo país, inclusive já testadas em campanhas anteriores. Toda essa complexidade envolve a manutenção da cadeia de frio para garantir a qualidade do imunobiológico. Nesse sentido, a atual metodologia escalonada de remessas de vacina contra COVID-19, adotada pelo Ministério de Saúde, não permite que os municípios atendam a totalidade das pessoas dos grupos prioritários em uma única remessa, exigindo um esforço maior dos estados e municípios para operacionalizar e avançar com a campanha.

Pode-se exemplificar essa dificuldade em territórios muito extensos ou com grandes dificuldades geográficas, como são os casos do Pantanal, Amazônia e territórios indígenas. Nesses casos, é necessário programar várias incursões com as vacinas, o que implica em um custo mais alto para os estados e municípios, além de dificultar o acesso oportuno das pessoas dos grupos prioritários que vivem nas regiões de mais difícil acesso, o que pode impactar negativamente na redução dos casos graves e da mortalidade por COVID-19.

As coordenações locais de imunização e as equipes de saúde devem elaborar planos compatíveis com a sua realidade para otimização da operação de campo, uma vez que necessita dispor de recursos materiais, logístico, humanos e insumos suficientes para dar celeridade a distribuição a partir de cada pauta de remessas distribuídas pelo PNI e equipamentos necessários para garantir a segurança térmica dos imunobiológicos na cadeia de frio e transporte das vacinas até o seu destino.

A maior parte das vacinas utilizadas até o momento no Brasil possuem esquema vacinal com duas doses, especificamente a vacina produzida pelo fabricante Butatan/Sinovac deve ser aplicada entre 14 e 28 dias após a aplicação da primeira dose, o que requer um grande esforço e organização dos serviços de saúde para assegurar o acesso e adesão de um número maior de pessoas a serem vacinadas em curto espaço de tempo entre as doses.

A vacina AstraZeneca/Fiocruz possui um intervalo maior entre as doses, podendo ser administrada em 12 semanas após a aplicação da primeira dose, sendo preferível seu uso em áreas remotas e de difícil acesso, considerando a facilidade logística esse maior intervalo entre doses, que possibilita a recomposição das equipes de saúde e a organização dos serviços para vacinação de campo. 
Outro desafio nesta campanha foi a adoção inédita do registro de identificação nominal e de outras informações cadastrais pessoais, que vem demandando maior tempo de atendimento nos postos de vacinação. Muitos estados e municípios desenvolveram sistemas próprios para captar dados de forma oportuna, possibilitando o monitoramento da evolução da campanha, uma vez que o sistema oficial do Ministério da Saúde, o SI-PNI - E-sus, não foram suficientes para suprir o volume de informações geradas ao mesmo tempo em todo o território nacional.

Por estarmos utilizando nesse momento novas vacinas, com aprovação acelerada pelos diversos órgãos regulatórios do mundo dada a situação de emergência em saúde pública, faz-se necessário estudar e entender o comportamento no decorrer da utilização em massa, muitos processos de trabalho já bem definidos e estabelecidos pelo PNI devem ser adaptados a essa nova realidade da campanha de vacinação contra a COVID-19, por exemplo, a implementação da vigilância de eventos adversos pós-vacinação ativa e a constante definição de critérios de prioridades pactuados nas instâncias intergestoras locais ou nacional, considerando a capacidade de produção nacional, a aquisição e o envio fracionado de doses a cada remessa de vacinas distribuídas aos estados e DF pelo Ministério da Saúde.

\section{CONSIDERAÇÕES FINAIS}

Atualmente, a vacinação é a estratégia mais efetiva e segura para que a humanidade vislumbre um caminho no enfrentamento da maior crise sanitária da história recente. De fato, as vacinas marcaram a trajetória da humanidade como uma das principais inovações que conseguiram poupar vidas e sequelas

Ademais, a pandemia da COVID-19 revelou de forma cristalina pontos de tensão e limitações do sistema de saúde, seja na rede pública ou privada de saúde. No caso do Brasil, o país não apenas acompanhou o amadurecimento histórico das políticas de vacinação, senão se apresentou como uma liderança no contexto mundial. Porém, o fato é que no que se refere a vacinação contra a COVID-19, observaram-se inúmeras ingerências decorrentes da politização da pandemia e das vacinas, o que culminou numa baixa disponibilidade da imunobiológicos, muitas incertezas e falta de comando no nível central. Por isso, a campanha contra a COVID-19 vem exigindo muito mais organização no nível municipal e estadual e dos trabalhadores da ponta.

\section{REFERÊNCIAS:}

1. Lima AA, Pinto ES. O contexto histórico da implantação do Programa Nacional de Imunização (PNI) e sua importância para o Sistema Único de Saúde (SUS). Scire Salutis, 2017;17(1):53-62. https://doi.org/10.6008/SPC2236-9600.2017.001.0005

2. Schatzmayr HG. A varíola, uma antiga inimiga. Cad Saúde Pública. 2001;17(6):1525-30. https://doi.org/10.1590/ S0102-311X2001000600024

3. Porto MY. Uma revolta popular contra a vacinação. Cienc Cult [Internet]. 2003[cited 2020 Apr 2];55(1):53-4. Available from: http://cienciaecultura.bvs.br/pdf/cic/v55n1/14861.pdf

4. Gonçalves G. Campanha de Erradicação da Varíola introduziu novo conceito de 'vigilância epidemiológica' no Brasil. Casa de Oswaldo Cruz, Fundação Instituto Oswaldo Cruz, 07 de maio de 2020[cited 2020 Sep 2]. Available from: http://coc. fiocruz.br/index.php/pt/todas-as-noticias/1787-campanha-de-erradicacao-da-variola-introduziu-novo-conceito-devigilancia-epidemiologica-no-brasil.html\#.YHhCVOhKjIV

5. Risi Jr JB. Campanha de Erradicação da Varíola introduziu novo conceito de 'vigilância epidemiológica' no Brasil. Entrevista concedida a Glauber Gonçalves em 07 de maio de 2020[cited 2020 Sep 2]. Casa de Oswaldo Cruz, Fundação Instituto Oswaldo Cruz. Available from: http://coc.fiocruz.br/index.php/pt/todas-as-noticias/1787-campanha-de-erradicacao-davariola-introduziu-novo-conceito-de-vigilancia-epidemiologica-no-brasil.htmI\#.YHhCVOhKjIV

6. Temporão JG. O Programa Nacional de Imunizações (PNI): origens e desenvolvimento. Hist Cienc Saude-Manguinhos. 2003;10(Supl.2):601-17. https://doi.org/10.1590/S0104-59702003000500008 
7. Silva Jr JB. 40 anos do Programa Nacional de Imunizações: uma conquista da Saúde Pública Brasileira. Epidemiol Serv Saúde. 2013;22(1):7-8. https://doi.org/10.5123/S1679-49742013000100001

8. Ministério da Saúde (BR). Secretaria de Vigilância em Saúde, Departamento de Vigilância das Doenças Transmissíveis. Manual de Normas e Procedimentos para Vacinação. Brasília: Ministério da Saúde; 2014. 176 p.

9. Ministério da Saúde (BR). Manual dos Centros de Referência para Imunobiológicos Especiais [Internet]. 5. ed. Brasília: Ministério da Saúde; 2019[cited 2020 Sep 2]. https://sbim.org.br/images/calendarios/manual-centros-referencia_ imunobiologicos-especiais-5ed-web.pdf

10. Domingues CMAS, Fantinato FFST, Duarte E, Garcia LP. Vacina Brasil e estratégias de formação e desenvolvimento em imunizações. Epidemiol Serviços Saúde. 2019;28(2):3. https://doi.org/10.5123/S1679-49742019000200024

11. Gadelha CAG, Braga PSC, Montenegro KBM, Cesareo BB. Acesso a vacinas no Brasil no contexto da dinâmica global do Complexo Econômico-Industrial da Saúde. Cad Saúde Pública. 2020;36(2):e00154519. https://doi. org/10.1590/0102-311X00154519

12. Domingues CMAS, Fantinato FFST, Duarte E, Garcia LP. Vacina Brasil e estratégias de formação e desenvolvimento em imunizações. Epidemiol Serv Saúde. 2019;28(2):3: e20190223. https://doi.org/10.5123/S1679-49742019000200024

13. Barbieri CAL, Couto MT, Abujamra FM. A (não) vacinação infantil entre a cultura e a lei: os significados atribuídos por casais de camadas médias de São Paulo, Brasil. Cad Saúde Pública. 2017;33( 2):e00173315. https://doi. org/10.1590/0102-311x00173315

14. Medeiros EAS. Entendendo o ressurgimento e o controle do sarampo no Brasil. Acta Paul Enferm. 2020;33:e-EDT20200001. https://doi.org/10.37689/acta-ape/2020EDT0001

15. Ministério da Saúde (BR). Boletim epidemiológico 16: monitoramento dos casos de arboviroses urbanas causados por vírus transmitidos pelo mosquito Aedes (dengue, chikungunya e zika), semanas epidemiológicas 1 a 16 [Internet]. Brasília: MS; 2021 [cited 2020 Sep 2]. https://www.gov.br/saude/pt-br/media/pdf/2021/maio/4/boletim_epidemiologico_svs_16-1.pdf

16. Sato APS. Qual a importância da hesitação vacinal na queda das coberturas vacinais no Brasil? Rev Saude Publica. 2018;52:96:1-9 https://doi.org/10.11606/S1518-8787.2018052001199

17. Fundação Instituto Oswaldo Cruz (FioCruz). Boletim Observatório Covid-19 [Internet]. 2021 [cited 2020 Sep 2]. Available from: https://portal.fiocruz.br/sites/portal.fiocruz.br/files/documentos/boletim_covid_2021_extraordinario_junho_parte1.pdf

18. Lima EJF, Almeida AM, Kfouri RA. Vacinas para COVID-19 - o estado da arte. Rev Bras Saude Matern Infant. 2021;21(Suppl-1):13-19. https://doi.org/10.1590/1806-9304202100S100002

19. Ministério da Saúde (BR). Secretaria de Vigilância em Saúde. Departamento de Vigilância das Doenças Transmissíveis. Plano nacional de operacionalização da vacinação contra a covid-19. Brasília: Ministério da Saúde; 2021 [cited 2020 Sep 2]. Available from: https://www.gov.br/saude/pt-br/coronavirus/publicacoes-tecnicas/guias-e-planos/plano-nacional-de-vacinacao-covid-19/view

20. Waldman EA, Sato HK, Freitas FRM. Epidemiologia Aplicada à Vacinação. In: Farhat CK, Weckx LY, Carvalho LHFR, Succi RCM (Editores). Imunizações: Fundamentos e Prática. 5a ed. São Paulo: Editora Atheneu; 2008. p.53-67.

21. Mizutaa AH, Succia GM, Montallia VAM, Succia RC. Perceptions on the importance of vaccination and vaccine refusal in a medical school. Rev Paul Pediatr. 2019;37(1):34-40. https://doi.org/10.1590/1984-0462/;2019;37;1;00008

22. Yamey G, Schäferhoff M, Hatchett R, Pate M, Feng Z, McDade KK. Ensuring global access to COVID-19 vaccines. Lancet 2020;395(10234):P1405-6. https://doi.org/10.1016/S0140-6736(20)30763-7

23. MacDonald NE, SAGE. Vaccine hesitancy: definition, scope and determinants. Vaccine. 2015;33(34):4161-4. https://doi. org/10.1016/j.vaccine.2015.04.036

24. Avaaz. Sociedade Brasileira de Imunizações. As Fake News estão nos deixando doentes? Como a desinformação antivacinas pode estar reduzindo as taxas de cobertura vacinal no Brasil [Internet]. 2019 Nov [cited 2020 Apr 2]. Available from: https://sbim.org.br/images/files/po-avaaz-relatorio-antivacina.pdf

25. Macedo LR, Struchiner CJ, Maciel ELN. Backdrop to the development of Brazil's national COVID-19 immunization plan. Cienc Saude Coletiva. 2021:26(7):2859-62. Available from: https://www.scielosp.org/article/csc/2021.v26n7/2859-2862/en/ 